\title{
Study on the Online Dispute Resolution System in China
}

\author{
Zhengmin $\mathrm{Lu}^{1, \text { a }}$, Xinyu Zhu ${ }^{1, \mathrm{~b}}$ \\ ${ }^{1}$ Law school , Xiamen University, No. 422, Siming South Road, Xiamen, Fujian, China \\ a luzhmin999@126.com, bxmuzhuxinyu@163.com
}

Keywords: ODR; ODR platform; trust problem; access challenge

Abstract. The development of internet leads the innovation of the dispute resolution. As the innovative achievements under the strategy of "Internet+", online dispute resolution (ODR) is increasingly applied to the resolution of the disputes. Since ODR are cheap, convenient and flexible, it seems appealing to potential users. However, the ODR system in China has many shortcomings. Therefore, it is crucial to construct the ODR mechanism according to the advanced experience overseas on one hand, and China's national conditions on the other.

\section{Introduction}

\section{The Definition of ODR}

Generally speaking, ODR (Online Dispute Resolution), which uses many modern information technologies, such as the technology of electronic information transmission, online video conference technology and online audio technology, is a new way to handle civil disputes. According to the Cross-border E-commerce Dispute Settlement Procedure drafted by the United Nations Commission on International Trade Law, the definition about ODR is a dispute settlement mechanism with the aid of electronic communications and other information technology.[1]Thus, ODR is mainly divided into five types, including online negotiation, online mediation, online arbitration, online complaints and online trial.

\section{The Development of ODR in Foreign Countries}

The history of ODR is only 30 years, and the first three pilot programs in US are Virtual Arbitration Program, Online Mediation Program in Maryland University and Online Appeal Program in Massachusetts University. After a period of running, ODR is considered to be an effective means of dispute resolution. Nowadays, ODR is accepted by people around the world. In accordance with the latest statistics, there are more than 100 websites that provide ODR service. In the initial development stage, the main field that ODR applied to was the e-commerce dispute between online sellers and online customers. With the mature of some relevant technologies, the applicable scope of ODR extended from online disputes to the offline disputes. For example, the scope of American Arbitration Association (AAA) online arbitration covers business disputes, labor disputes, disputes caused by hurricane insurance, and so on.[2]In addition to the cases in US, EU is also devoted to establishing a unified ODR platform for EU members, in order to promote the development of e-commerce industry and enhance consumers' confidence in e-commerce. On March 12, 2013, European Parliament and European Council enacted the regulations about 
consumer dispute settlement online, which decided to establish the ODR platform since January 2016.

\section{The Development of ODR in China}

In China, ODR started relatively late. In 2000, China's first ODR platform called Domain Name Dispute Resolution Center is established. After that, ODR in China developed slowly because ODR did not draw adequate attention from the academic and practical fields. However, "Internet+" strategy which is put forward recently promotes the development of ODR. Since 2016, the Supreme People's Court has successively promulgated several official documents, such as the Opinions on Deepening the Reform of the Diversified Dispute Settlement Mechanism and the Notice about Carrying out Online Mediation Platform Programs in Some Areas.

In practice, local people's courts and governments carry out the exploration on ODR in accordance with the requirements of the Supreme People's Court. So far, China's ODR platforms can be categorized into four main groups: (1) professional ODR platforms. This kind of platform is specialized in ODR. For instance, CIETAC's Domain Name Dispute Resolution Center and Guangzhou Arbitration Commission's online arbitration platform are the institutes concentrated on ODR. (2)ODR platform dominated by people's court. At present, these platforms can be divided into two major types. The first is online mediation platform and the second is online trial platform. With Sina's cooperation, many local courts set up the online mediation platforms called "E-mediation". The system can be found in Chengdu Intermediate People's Court, Hefei Intermediate People's Court and Shanghai Maritime Court. Besides, in 2015, the Supreme People's Court decided to launch online trial pilot programs in Jilin and Zhejiang provinces. (3)ODR platform dominated by judicial administrative departments. As generally acknowledged, judicial administrative departments in China are responsible for maintaining social harmony and stability. On the basis of these functions, the judicial administrative departments set up ODR platforms with people's conciliation committee, media and other institutes. For example, Chongqing Judicial Bureau along with Chongqing Broadcasting Group established the online mediation platform called "Bayu Peacemaker". (4)ODR platforms established by E-commerce websites. Such online dispute resolution platforms are mainly used for coping with online shopping disputes between online consumers and online sellers. For example, Taobao, Jingdong and Gome have their own ODR mechanisms. The following chart demonstrates the status quo of several ODR platforms according to the statistics provided by related newspapers and journals. 


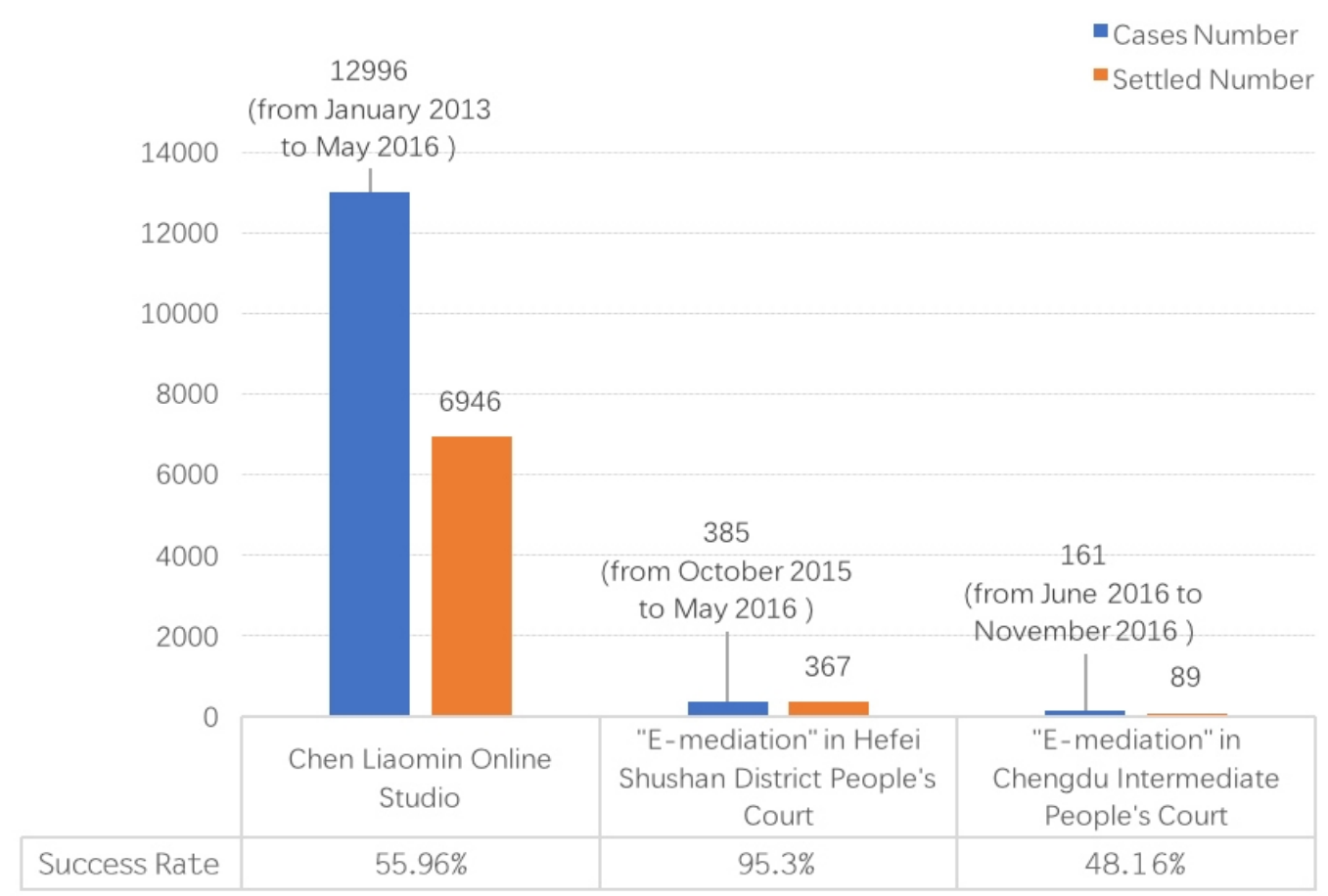

Chart 1 The Statistics about the Number of Cases Accepted by Some ODR Platforms

\section{The Necessity and Feasibility to Introduce ODR in China}

\section{The Increasing Number of Online Disputes}

In 2015, the transaction amount of E-commerce in China reached 18.3 trillion, which makes China surpass US to become the world's largest online retailing market. But the number of online disputes have been surging over past few years accordingly. In the first three quarters of 2015, the industry and commerce administrative authorities in China has received over 105000 online shopping complaints, accounting for $26.2 \%$ of the total consumer's complaints. There is no doubt that the increasing number of the online disputes presents a strong demand to apply and develop ODR.

\section{The Change of the Dispute Resolution Concept}

The advancement of the society and economy brings the change in the concept of dispute resolution. People no longer pursue the result of dispute settlement only, but pay more attention to the efficiency and effectiveness about the dispute resolution procedure. Mauro Cappelletti, an Italian civil procedure professor, summarized the basic concepts of modern civil procedure as procedure guarantee and access to justice.[3]User-friendly and convenient dispute solving service can provide a shortcut to access to justice.[4]In recent years, China has emphasized on optimizing the dispute settlement mechanism in order to help parties to cope with their disputes effectively. And ODR is a modern problem-solving way which can achieve the goals as such. 


\section{The Popularity of the Internet and Connected Devices}

Recently, the number of Chinese internet users grows gradually. China internet development report demonstrates that until December 2016, there are 731.25 million internet users, including 695.31 million mobile internet users. The chart below shows the change of Internet users, mobile internet users from 2012 to 2016.

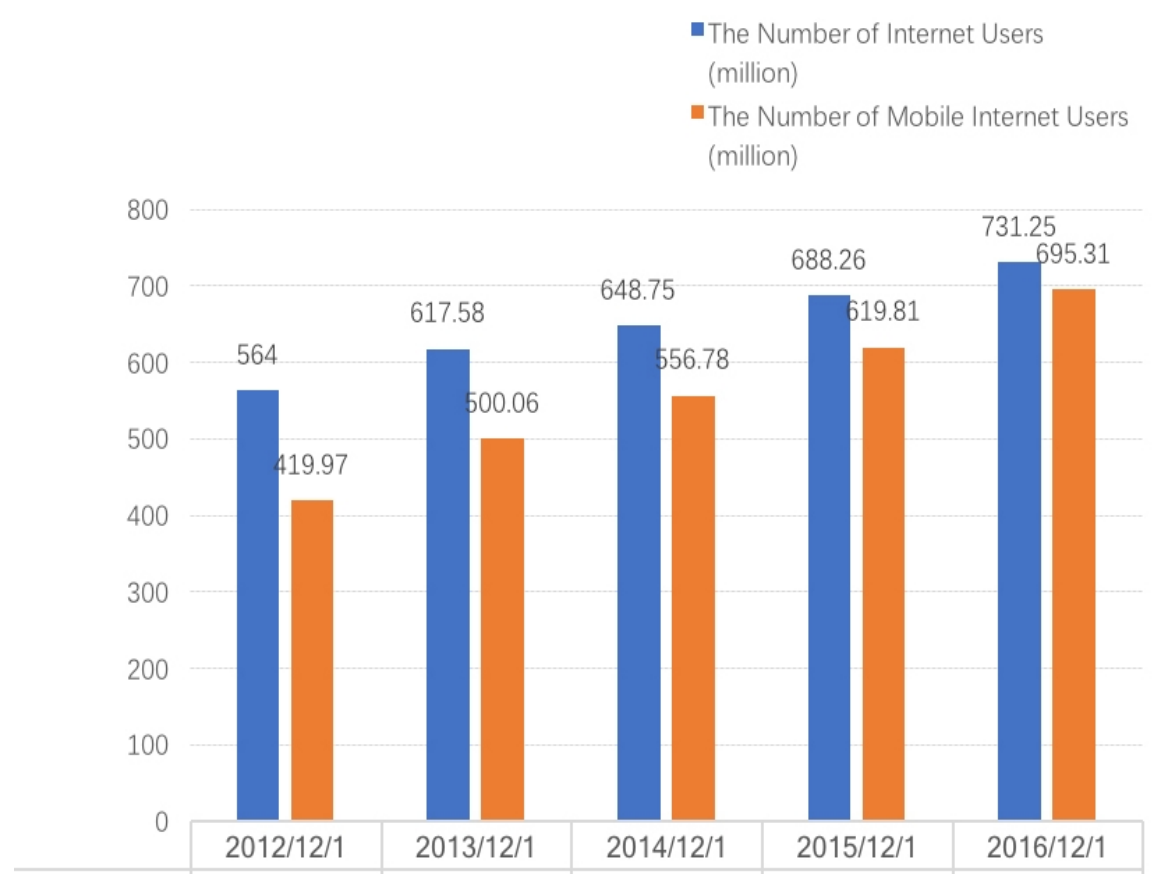

Chart 2 The Statistics about the Internet Development in Recent 5 Years

In addition, the connected devices like mobile phone, laptop and computer become more and more common. That means it is possible for potential users to access to the ODR service.

\section{The Improvement of Electronic Information Technology}

In the era of "Internet+" , a great number of new technologies are invented, which offers technical support for ODR.[5]Electronic signature and voiceprint recognition have been applied in the field of personal identification; firewalls and security keys can secure the confidence of useful information; electronic transmission technology can be used to deliver electronic document; database technology is of convenience for storing the evidence material; online payment technology can make it easier to pay relevant fees; instant message applications provide various ways of communication. Thanks to these technologies, ODR steps from fantasy to reality.

\section{The Drawbacks of ODR in China}

\section{Single Function of the ODR Platform}

In practice, the function of ODR platform is quite single and there is no comprehensive ODR platform at present. Most of the existing ODR platforms can only mediate or arbitrate disputes, only a few ODR platforms can be used for both mediation and arbitration or both mediation and litigation. The single function of ODR platforms can hardly meet various needs of parties and 
handle their disputes at one time. The internet's greatest contribution is that it enables people to integrate various resources, meanwhile realizing the information sharing. Nevertheless, the single function of ODR platforms not only causes a waste of dispute-resolution resources, but also deviates the information sharing spirit.

\section{The Uncertainty Scope of ODR}

It is an inevitable trend to handle the offline disputes on the internet in China, but it does not mean that all types of disputes are suitable for ODR. What kind of disputes are fit for ODR? What kind of disputes are not fit for ODR? There is no clear answer to these questions. In practice, Chengdu E-mediation only accepts the cases with clear facts, few evidences and little controversy. That mainly contains seven kinds of disputes, including traffic accident liability disputes, family disputes, folk lending disputes, labor disputes, rural neighboring right disputes, consuming disputes and intellectual property disputes. On the one hand, the clear scope of ODR can play a positive role to guide people to give priority to select ODR and thus relieve the burden of other means of dispute resolutions; on the other hand, it can achieve the optimal allocation of the dispute resolution resources and make the court spare more time to study the complex cases.

\section{Trust Problem}

Trust is the premise for procedure to run smoothly. However, in the internet space, people unavoidably lack mutual understanding and trust. So, it is particularly crucial for people to trust ODR. The trust of ODR is mainly reflected in the external environment and the ODR itself. To be honest, the severe Internet security environment and the unfamiliar with ODR cause the trust crisis of ODR. The openness and anonymity of the Internet increases the potential risks, such as hacker attacks, personal information leakage and internet fraud. Complicated internet environment hinders people to distinguish between the true messages and false messages. Hence, people's distrust for internet will not be eliminated in the short time.

As for the ODR itself, most people do not have full knowledge of the ODR. Consequently, a large number of people have doubts about ODR. These doubts are mainly focused on five aspects. First, whether ODR can truly solve the disputes among the parties through the virtual world. Second, whether online mediators or online arbitrators treat both parties neutrally and impartially. Third, whether ODR procedure can protect the substantive interests and procedural interests. Forth, if the parties choose ODR, whether he or she knows how to operate it. Fifth, if the parties do not know how to operate ODR, whether he or she can get necessary assistance in time.

\section{Access Challenge}

Accessibility is the main character to measure whether ODR is convenient or not. Even if the internet infrastructure construction in whole China has been gradually improved, but we should not ignore the unbalanced regional economic development in different areas. Different levels of economic development in different areas directly affect the development of the internet infrastructure construction. Chart 3 indicates the rate of internet penetration in different zones. The divergence make people in remote areas have little possibility to access ODR. 


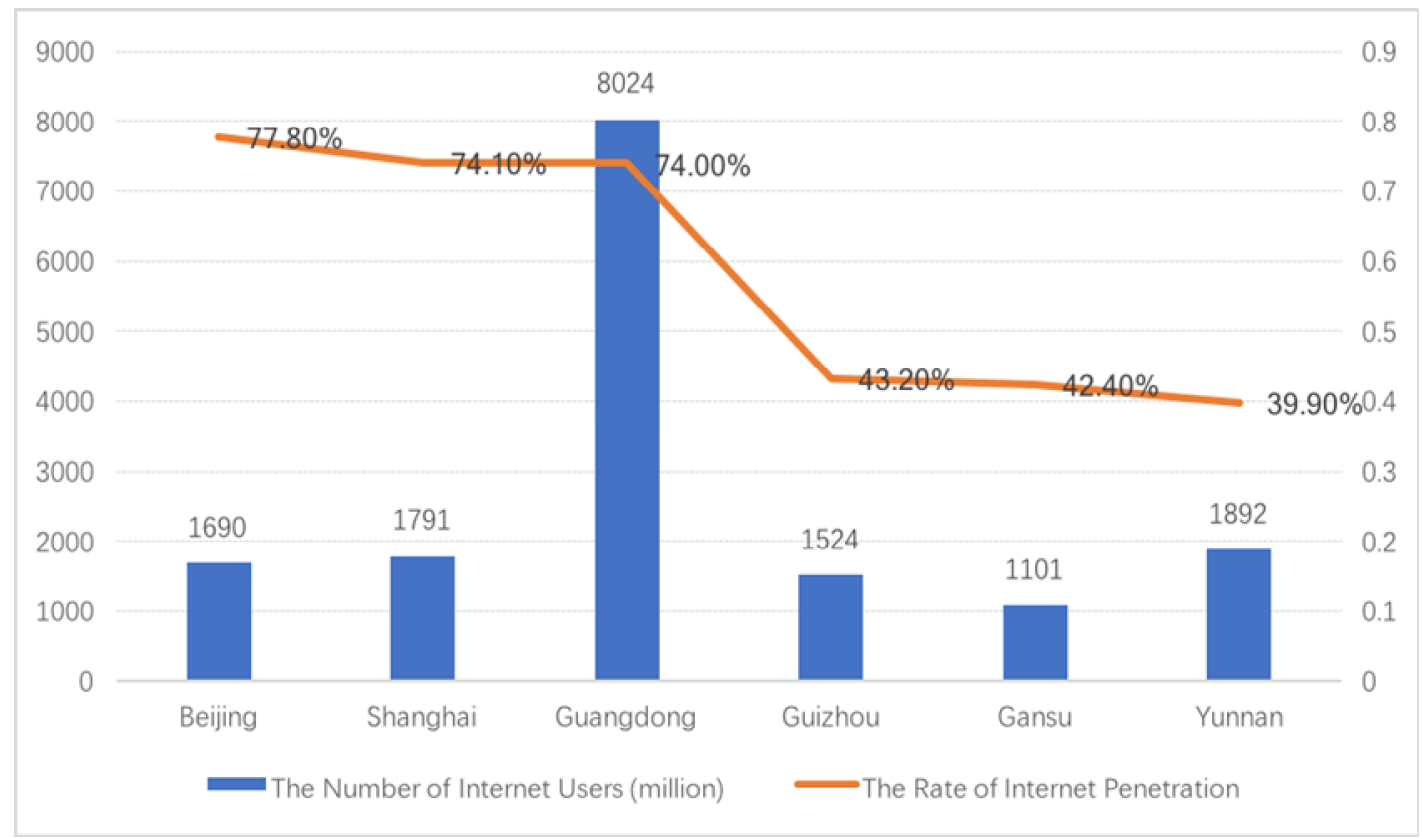

Chart 3 The Rate of Internet Penetration in Different Zones

\section{The optimization of ODR in China}

\section{Establish a one-stop ODR platform}

Under the background of the "Internet+", we should make full use of the Internet resources in the charge of social comprehensive governance. One-stop ODR platform is a blend of ideas of exchange and share, which becomes a future trend of ODR in China. The Supreme People's Court also explicitly supports the innovation of ODR. One-stop ODR platform refers to the multifunctional ODR platform which integrates the online mediation, online arbitration, online complaints, online trail and etc. The significance of one-stop ODR platform lies in three aspects. First, it will be able to give parties multiple choices. Second, it can promote the ability to handle the civil disputes and promote the successful rate to resolve disputes. Third, it can enable professional talents to serve people across the country.

From the feasibility of the technical operation, we can consider to establish a ODR platform nationwide and adjust details with regard to the regions and types of dispute resolution. This can avoid the repeated construction of ODR platform, connect the litigation and non-litigation mechanism and promote the development of various means to solve disputes.[6]

\section{Specify the Scope of ODR}

In combination with the existing ODR practice and the nature of ODR, the following three types of disputes are suitable to solve through the ODR: (1) The civil disputes that only involved with money. In general, this type of disputes is always simple and the means of shouldering the responsibility contains pay the damages, penalty. Thus, it can achieve the full electronic procedure from the application to execution. (2) The disputes that people are reluctant to expose identity and communicate face-to-face. This kind of disputes mainly cover family disputes, adjacent disputes and disputes involving privacy. (3) The disputes that have obvious advantages settled through ODR. This kind of disputes can be subdivided into two classes. The first is the disputes that parties located 
in different locations. The second is online disputes, such as electronic commerce disputes, P2P disputes and online intellectual property rights disputes. Except for the above disputes, if both parties voluntarily choose ODR, other types of disputes can be settled through ODR.

Another scope should be specialized is the territorial range of ODR. Whether from the number of netizens or the number of online disputes, eastern developed regions are higher than that of western regions. Therefore, like other reform measures, ODR could select a number of eastern provinces and municipalities that have a high level of economic development to carry out the experimental projects. By summarizing the practical experience and lessons, ODR can promote in whole China when the opportunity is mature. In fact, in February 2017, the Supreme People's Court enacted a notice about carrying out the online mediation platform programs in some courts. That notice determined six superior people's courts (Beijing, Hebei, Shanghai, Zhejiang, Anhui, Sichuan) as testers.

\section{Improve the Relevant Supporting Measures}

The supporting measures are essential to the ODR development. So, Information security technology, information disclosure mechanism should be used.

ODR platforms are responsible for keeping the secret of the mediation agreements, arbitral awards and the relevant evidences. However, the openness of Internet exacerbates the risk of information disclosure. This requires using a variety of information security technology to ensure the safety of information. At present, the most commonly used security measures is the secure sockets layer, it can provide a safe and reliable information transmission channel. And one of the most specific character is a lock symbol on the web address.[7]Besides, the encryption of public key is another technology used in data protection. The system uses the public and private keys for data encryption and decryption respectively. In 2011, German enacted email account law, which introduces the email account specialized for the e-court. This account can only be provided by the online service providers that authorized by the official government. Right now, part of the courts in China conduct a similar exploratory practice. For example, Jilin e-court designates 163 mail as the third-party mail system to receive information. If the specified email system can pass the safety certification by the relative administrative departments, then it resembles with the account for the German e-court. In the near future, the one-stop ODR platform can take such email system into the consideration.

The purpose of information disclosure is to make the public better understand ODR platform and enhance the trust in ODR. In order to ensure the transparency of ODR platform, it shall be announced the following information: (1)the applicable rules of procedure in ODR platform; (2)the list of online mediators, arbitrators and judges that including the name, education backgrounds and working experience; (3)the charging standard of ODR platform; (4)the legal effects and relief procedure of ODR platform; (5)annual report of ODR platform; (6)the common consulting problems and contact number of ODR platform.

\section{Innovate the Form of ODR Platform}

In line with the $38^{\text {th }}$ China Internet development report, $92.5 \%$ netizens and $38.5 \%$ netizens access the Internet through the mobile phone and laptop respectively. Nowadays, the existing ODR platforms only provide web version. In order to facilitate the parties, the form of ODR platform should keep pace with the times and provide a variety of ways to access it. Obviously, they don't adapt to the current situation that most people use mobile phone to surf the Internet. Based on that, 
the ODR platform should create a web version and a APP version and let people to choose a version according to their preference. Chongqing "Bayu Peacemaker" APP and Xiamen Haicang online mediation APP provide good models on the design of the mobile phone version.

\section{Conclusions}

As a new dispute resolution method, ODR greatly broadens the type of dispute resolutions and make the dispute solutions become more diverse. And the increasing number of online disputes, the change of the dispute resolution concept, the popularity of the Internet and connected devices, and improvement of electronic information technology provide a favorable environment for ODR. There is no denying that as any kind of emerging system, ODR in China still has many drawbacks, such as single function, uncertain scope, trust problem and access challenge. In this regard, we should set up one-stop ODR platform, specify the scope, improve the support measures, and innovate the form in order to smoothly operate the ODR mechanism, and make it gain popularity among people, especially young adults.

\section{References}

[1] Ding Ying. Online court: a new way to handle the small electronic commerce dispute[J]. Journal of Jinan University (philosophy and social science edition), 2015, (10):41-59. (in Chinese)

[2] DebiMiller-Moore. ODR at the AAA: online dispute resolution in practice[J]. University of Toledo Law Review, 2006, (2):87-91.

[3] Mauro Cappelletti. The party's right of essential procedural guarantee and future civil action[M]. Beijing: Law Express, 2000:5. (in Chinese)

[4] Long Fei. The development status and future prospects of ODR in China[J]. Law Application, 2016, (10):2-7. (in Chinese)

[5] Liu Jiaqi. The study on the change of legal limitation under the big data era[J]. Hubei Social Science, 2015, (7):140-146. (in Chinese)

[6] Chen Guomeng. Promote the construction of ODR[N]. People's Court Daily, 2016-12-28 (5). (in Chinese)

[7] Gao Wei. The study on the online arbitration[N]. Journal of Shanghai Jiaotong University (philosophy and social science edition), 2014, (6):18-25. (in Chinese) 